\title{
RFLP anàlysis of mitochondrial DNA from cytoplasmic male-sterile lines of pearl millet
}

\section{JA\#1416}

Received: 18 Fcbruary 1993 / Accepted: 14 September 1993

\begin{abstract}
Mitochondrial DNA (mtDNA) from 13 cytoplasmic male-sterile $(\mathrm{cms})$ lines from diverse sources were characterized by Southern blot hybridization to pearl millet and maize mtDNA probes. Hybridization patterns of mtDNA digested with Pst I, BamHI, Smal or $X$ hol and probed with 13.6-, 10.9-, 9.7- or $4.7-\mathrm{kb}$ pearl millet mtDNA clones revealed similarities among the cms lines 5141 A and ICMA 1 (classified as the S-A1 type of cytoplasm based on fertility restoration patterns), PMC 30A and ICMA 2. The remaining $\mathrm{cms}$ lines formed a distinct group, within which three subgroups were evident. Among the maize mitochondiral gene clones used, the coxI probe revealed two distinct groups of cytoplasms similar to the pearl millet mtDNA clones. The at $p 9$ probe differentiated the cons line $81 \mathrm{~A} 4$, derived from $P$. glaucum subsp. monodii, while the coxII gene probe did not detect any polymorphism among the $\mathrm{cms}$ lines studied. MtDNA digested with BamHI, PstI or $X$ hol and hybridized to the at $p 6$ probe revealed distinct differences among the cms lines. The maize atp6 gene clone identified four distinct cytoplasmic groups and four subgroups within a main group. The mtDNA fragments hybridized to the atp6 gene probe with differing intensities, suggesting the presence of more than one copy of the gene in different stoichiometries. Rearrangements involving the coxI and/or rrn18-rrns genes (mapped within the pearl millet clones) probably resulted in the S-A1 type of sterility. Rearrangements involving the at $p 6$ gene (probably resulting in chimeric form) may be
\end{abstract}

Communicated by $R$. Hagemann

R. Rajeshwari - N. C. Subrahmanyam (『)

School of Life Sciences, University of Hyderabad, Gachibowli, P. O. 500134 , India

\section{S. Sivaramakrishnan}

International Crops Research Institute for the Semi-Arid Tropics, Patancheru, A. P. 502 324, India

R. L. Smith

Agronomy Department, University of Florida, Gainesville, FL 32611, USA responsible for male sterility in other $\mathrm{cms}$ lines of pearl millet.

Key words RFLP - Mitochondrial DNA • Cytoplasmic male sterility - Pearl millet

\section{Introduction}

Cytoplasmic male sterility $(\mathrm{cms})$ is the inability of plants to produce viable pollen while being female fertile. The trait is maternally inherited, indicating that the factors responsible are present on the organellar genome. Cumulative evidence indicates that variations in the mitochondrial genome are associated with male sterility (Hanson and Conde 1985).

Pearl millet is an important cereal and forage crop of the semi-arid tropics and is widely grown in India. The development of cytoplasmic male-sterile lines by pearl millet breeders has facilitated the production of commercial hybrids, therby leading to increased yields. The introduction of the 'HBI' hybrid, obtained by using $\mathrm{cms}$ line Tift $23 \mathrm{~A}$, led to the doubling of pearl millet production between 1965 and 1970 (Burton 1983). However, the extensive use of a single cytoplasm results in genetic vulnerability to prevailing pathogens, as became cvident in maize where the use of cms-T cytoplasm led to a Southern leaf blight epidemic caused by Bipolaris maydis in the early 1970s, thereby necessitating the search for new sources of cytoplasms. The conventional method of classifying cytoplasms on the basis of fertility restoration patterns is cumbersome and time consuming. Restriction fragment length polymorphism (RFLP) of mitochondrial DNA (mtDNA) provides a suitable tool to assess the heterogeneity in the male-sterile cytoplasms. This technique has been successfully used for the classification of male-sterile cytoplasms in maize (borck and Walbot 1982), sorghum (Bailey-Serres et al. 1986) and sugar beet (Weihe et al. 1991).

Fertility restoration patterns distinguished the S-A1, $S-A 2$ and $S-A 3$ cytoplasms in pearl millet (Burton and 
Athwal 1967). A stable male-sterile cytoplasm was subsequently isolated from $P$. glaucum subsp. monodii (Maire) by Hanna (1987). The S-Al to S-A4 cytoplasms were differentiated following hybridizations of BamHIdigested muDNA to the maize atp6 gene probe (Smith and Chowdhury 1989). Several stable cms lines from diverse source have been identified in pearl millet and are currently being used in a breeding program at the International Crops Research Institute for the SemiArid Tropics (ICRISAT), India. The study presented here was undertaken to define RFLPs in the mtDNA using $13 \mathrm{cms}$ lines of pearl millet following Southern blot hybridizations to pearl millet and maize mtDNA clones.

\section{Materials and methods}

\section{Plant material}

The pearl millet accessions used in the study were $5141 \mathrm{~A}$. developed by repeated backcrossing of a downy mildew-resistant donor 1587 to Tift $23 \mathrm{~A}$ (Pokhriyal et al. 1976): ICMA 1(81 A), derived by inducing mutations in Tift 23 DB (Andrews and Anand Kumar 1982): ICMA 2 ( 843 A); L67 A. a cms line described by Burton and Athwal (1967); DSA 59-1. DSA 105. DSA 118. DSA 134 and DSA 144.1. germ plasm accessions from Ghana; and PMC 23 and PMC 30, from Botswana. The male-sterile (A) and their inbred maintainer $(B)$ lines from Ghana and Botswana were identified by Appa Rao et al. (1989) 81 A4 and ICMA 88001 were derived from Penniserum glaucum subspecies monodii (Maire) Brunken (Hanna 1987) and P. riolacelum (Lam.) L. Rich. (Marchais and Pernes 1985), respectively. All of the male-sterile lines were from the International Crop Research Institute for the Semi-Arid Tropics (ICRISAT) Hyderabad. India.

\section{Clones used}

The pearl millet mtDNA clones consisted of four PstI fragments, cloned and characterized from the S-AI system of sterility (Smith and Chowdhury 1991). The maize clones were $F_{1} \cdot F_{0}$ ATPase subunit 6 (atp6: Dewey et al. 1985a) and subunit 9 (atp9; Dewey et al. 1985b). kindly supplied by CS Levings III, Genetics Department. North Carolina State University, Raleigh, N. C. USA and cytochrome c oxidase subunit I (coxI: Isaac et al. 1985) and subunit II (coxll; Fox and Leaver 1981) a gift of CJ Leaver. Department of Plant Sciences. University of Oxford. U.K.

\section{MIDNA extraction, digestion and Southern transfer}

Mitochondrial DNA from pearl millet was purified according to the procedure described by Smith et al. (1987). It was then treated with restriction enzymes BamHI, Pstl, Sinal and Xhol according to the supplier's instructions in the presence of RNaseI $(15 \mu \mathrm{g} / \mathrm{ml})$. The reaction was terminated by the addition of BPB solution $(25 \%$ sucrose, $0.1 \%$ Bromophenol blue and $20 \mathrm{mM}$ EDTA). MIDNA fragments were separated by electrophoresis in a $0.8 \%$ agarose horizontal slab gel ( $5 \mathrm{~mm}$ thick) at $2 \mathrm{~V} / \mathrm{cm}$ for $16 \mathrm{~h}$ in TBE buffer (89 $\mathrm{mM}$ Tris, $89 \mathrm{mM}$ boric acid and $2 \mathrm{mM}$ EDTA, pH 8.3). Hindlllgenerated Lambda DNA fragments were used as standard molecular weight markers. The gels were stained in $0.5 \mu \mathrm{g} / \mathrm{ml}$ ethidium bromide for $40 \mathrm{~min}$ and destained for $5 \mathrm{~min}$ in deionized water. The gels were viewed on a UV transilluminator and photographed using Kodak Wratten Nos. 2B and 23A filters with type 667 Polaroid film. The Southem blot iransfers of DNA fragments onto nylon membrane (Genescreen, Dupont) were performed using the Vacugene blotting apparatus (Pharmacia) according to the manufacturer's protocol.
The blots were washed in $3 \times \mathrm{SSC}(1 \times \mathrm{SSC}=0.15 .11 \mathrm{NaCl} 0.015 .11$ sodium citrate. $\mathrm{pH} 7.0$ ) air-dried and baked at $80^{\circ} \mathrm{C}$ under vacuum for $1 \mathrm{~h}$.

Probe labelling and Southern hybridization

Purified inserts from various miDNA clones were labelled with alpha [32 P]-deoxycytidine $5^{\prime}-t$ riphosphate $\left(\left[{ }^{32} \mathrm{P}\right] \cdot d C T P\right)$ using the random-primed DNA labelling kit from Boehringer Mannheim and applying the method of Feinberg and Vogelstein (1983). Filter hybridizations were conducted according to Smith et al. (1989). Hybridized nylon filters were washed twice in $3 \times$ SSC containing $0.1 \%$ SDS at $65^{\circ} \mathrm{C}$ for $15 \mathrm{~min}$ each, and autoradiography was conducted at -70 : $C$ for various exposure times using $X$-ray filıns and intensifying screens.

\section{Cluster analysis}

The fragment sizes were determined using standard molecular weight markers. Similarity index matrices were generated based on the proportion of common restriction fragments between two lanes ( $\mathrm{Nei}$ 1987) using the formula

$F=\frac{2 M x y}{M x+M y}$

where $F$ is the similarity index:.$/ x$, the number of fragments in one accession; My. the number of fragments in a second accession; and Mxy. the number of fragments common to both accessions.

The value of 1.0 would mean that the patterns in the two accessions are identical. The data are represented in the form of matrices of order $n \times n$ where ' $n$ ' is the number of accessions. The genetic analysis was based on the expression of similarity of objects and respective groups by the agglomerative method of hierarchical clus. tering lechnique. which proceeds by a series of successive fusions of the ' 1 ' objects into clusters. Initially, each object is considered to be a separate member of a cluster. The two objects having the maximum similarity index are then grouped together, and proximities between each of the remaining objects and the two membered cluster is calculated according to the single linkage method. A computer program written in high-level language ' $C$ ' was used to construct the dendrograms.

\section{Results}

\section{MtDNA restriction patterns}

Restriction patterns of mtDNA purified from soft stem internodes of field-grown plants of the $\mathrm{cms}$ line PMC30A and its maintainer PMC 30B restricted with PstI, BamHI or HindIII showed differences between A and $B$ lines (Fig. 1) The $P$ st I restriction pattern revealed differences in two fragments in each of the $A$ and $B$ lines. The BamHI digestion yielded only a single fragment difference, while HindIII showed a difference of two fragments in A and one fragment in B line.

The restriction patterns of etiolated seedlings of some of the A and B lines were complex, and the low-molecular-weight fragments were not clearly resolved. The quality of mtDNA varied among different preparations depending on the genotype and source of tissue used for extraction. In general, miDNA obtained from soft stem tissues showed better restriction patterns than that obtained from etiolated seedlings. 


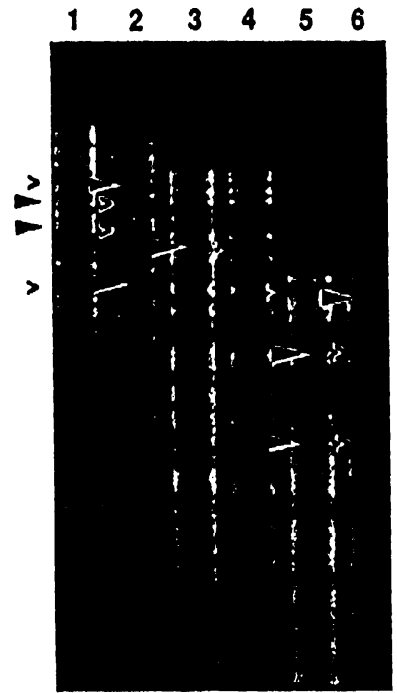

Fig. I Restriction fragment patterns of Pstl-(lanes 1,2). BamHI(lanes 3,4) or HindllI-(lanes 5,6) digested miDNA from PMC 30A (lanes $1,3,5$ ) and PMC 30B (lanes $2,4,6)$. Note the presence (D)/absence ( $>$ ) of fragments

\section{Hybridizations of mtDNA with homologous clones}

Hybridization patterns of mtDNA digested with PstI, $B a m H I, S m a I$ or $X h o I$ and hybridized to any one of the four pearl millet clones distinguished one group of cytoplasms consisting of $\mathrm{cms}$ lines 5141, PMC 30, ICMA 1 and ICMA 2 (Group I) from the remaining cytoplasms consisting of cms lines L 67, PMC 23, DSA 59-1, DSA 105, DSA 118, DSA 134 and DSA 144-1 (Group II). The cms lines of Group I were characterized by the presence of a 4.7-kb Pst I fragment instead of the $10-\mathrm{kb}$ fragment present in the Group II when hybridized to 13.6-, 10.9- and 4.7-kb clones (Fig. 2a, b, d). Additional fragments hybridizing to each of these clones were common to all cytoplasms. The $9.7 \cdot \mathrm{kb}$ clone, however, hybridized to the 10-kb Pst I fragment in Group II cms lines, but the $4.7-\mathrm{kb}$ fragment hybridizing to the other three pearl millet clones was absent in the Group I cytoplasms (Fig. 2c).

MiDNA digested with $B a m \mathrm{HI}$ and probed with any one of the four clones revealed a 6-kb fragment in the Group II cytoplasms (Fig. 3), whereas the Group I cytoplasm (represented by $5141 \mathrm{~A}$ in Fig. 3, lane 3) was characterized by a relatively higher intensity of a $4.9-\mathrm{kb}$ fragment, suggesting additional fragments of this size. The maintainer lines of Group I and II showed the $6-\mathrm{kb}$ fragment.

A distinct $7.5-\mathrm{kb}$ SmaI fragment hybridizing to all four clones was observed in Group I cms lines (represented by $5141 \mathrm{~A}$ and $\mathrm{PMC} 30 \mathrm{~A}$ ), whereas the remaining cms lines showed a 6-kb fragment instead (Fig. 4). Various other fragments hybridizing to the four clones were common to all the cytoplasms.

Southern blot hybridization of the four clones to the $X$ hol digests of mtDNA revealed a $20-\mathrm{kb}$ fragment in Group I cms lines (represented by $5141 \mathrm{~A}$ and PMC $30 \mathrm{~A}$ ) instead of the $7-\mathrm{kb}$ fragment present in the remaining cytoplasms (Fig. 5). All of the cytoplasms had several common fragments hybridizing to each of these clones.

\section{Hybridizations of mtDNA with heterologous clones}

The maize atp 9 gene probe distinguished $\mathrm{cms}$ line $81 \mathrm{~A} 4$ from the remaining cytoplasms by hybridizing to a 7.6-kb Xhol fragment (Fig. 6 lane 9) not present in the other cms lines as well as to the 4.6- and 5.4-kb fragments present in all of the cytoplasms. The maize coxI probe distinguished Group I cytoplasms from the remaining $\mathrm{cms}$ lines (similar to the four pearl millet clones). This probe produced a distinct pattern with mtDNA from ICMA 88001 (Fig. 7, lane 6). The maize coxII gene probe did not show polymorphism among the various cms lines (data not shown).
Fig. 2 Southern hybridization of Pstl-digested miDNA from ICMA 1 (lane 1, representative of group 1 cytoplasms) and ICMB I (lane 2, representative of group II cytoplasms) hybridized to the pearl millet clones. a $13.6 \mathrm{~kb}, b 10.9 \mathrm{~kb}$, c $9.7 \mathrm{~kb}, \mathrm{~d} 4.7 \mathrm{~kb}$. Arrows indicate presence $(\Delta) /$ absence $(>)$ of fragments

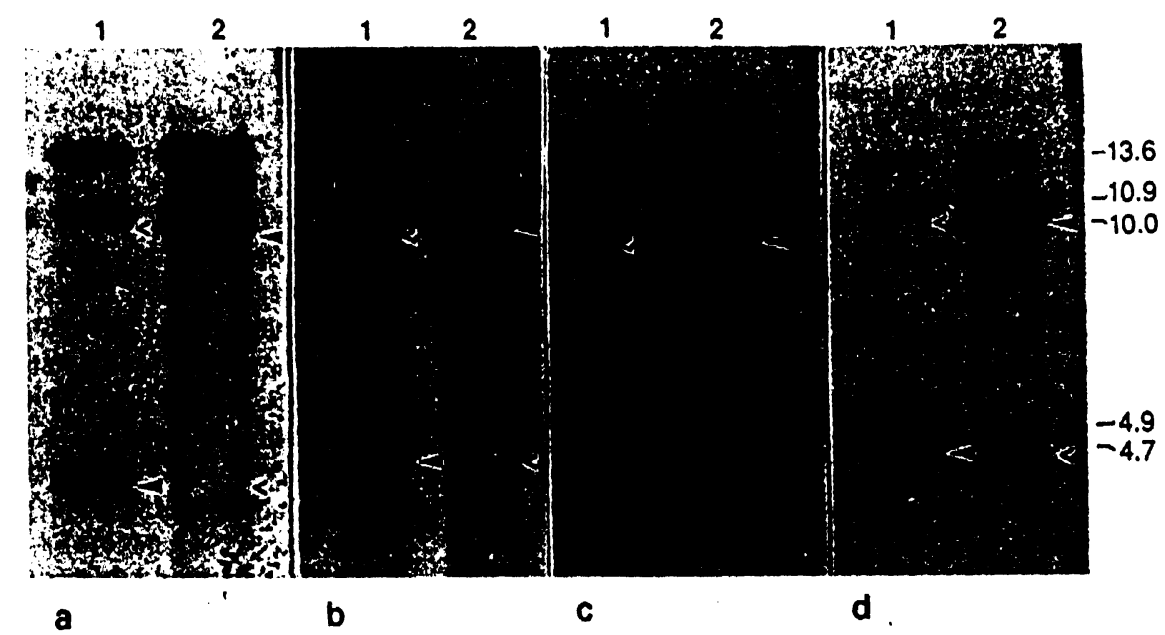


Fig. 3 Autoradiogram of 13.6$k b$ pearl millet clone hybridized to BantHI-digested miDNA from $\mathrm{cms}$ lines. Lanes $I$ and 2 PMC $23 \mathrm{~A}$ and $\mathrm{B}, 3$ and 45141 $A$ and $B, 5$ and 6 DSA $105 A$ and B. 7 and 8 DSA 134 A and B, 9 and $10 \mathrm{~L} 67 \mathrm{~A}$ and $\mathrm{B}, 11$ and 12 DSA 59-1 $A$ and $B$. Note the absence ( $>$ ) of a $6-\mathrm{kb}$ fragment and the increased intensity of the $4.9-\mathrm{kb}$ fragment in $5141 \mathrm{~A}$ (lane 3)

Fig. 4 Hybridization patterns of the $13.6-\mathrm{kb}$ pearl millet clone with Smal digests of $m t D N A$ from $\mathrm{cms}$ and their maintainer lines. Lanes $I$ and 2 PMC $23 \mathrm{~A}$ and $B, 3$ and 45141 A and B. 5 DSA 134 A. 6 and 7 DSA 105 A and $\mathrm{B}, 8$ and $9 \mathrm{PMC} 30 \mathrm{~A}$ and $\mathrm{B}$. 10 and $1 /$ DSA $118 \mathrm{~A}$ and $\mathrm{B}, 12$ and 13 DSA $144-1 A$ and $B$. Note the presence ( $\rightarrow$ ) of a 7.5. $\mathrm{kb}$ fragment and the absence $(>)$ of a 6-kb fragment in $5141 \mathrm{~A}$ ard PMC 30A llanies 3 and 8 . respectively!
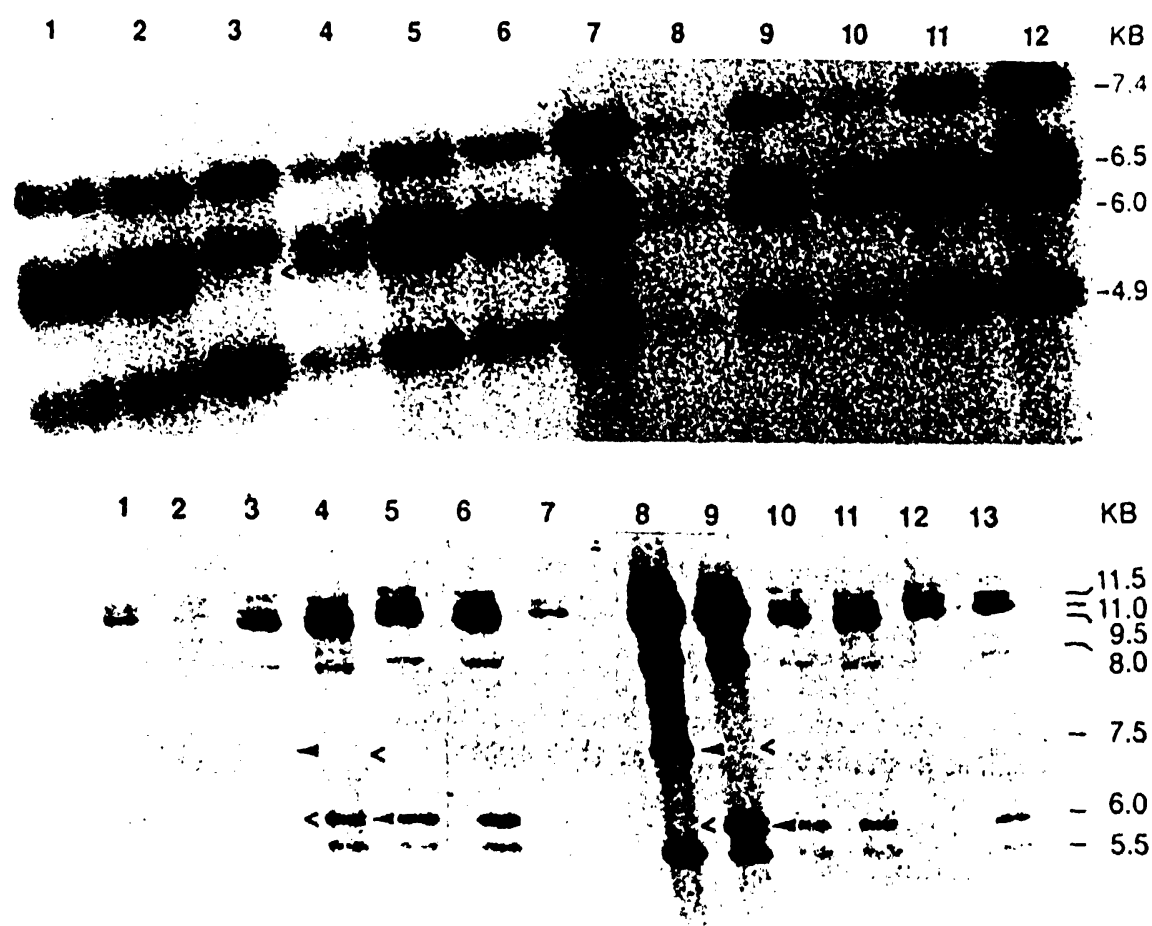

Further polymorphisms were detected among the cms lines following the hybridization of Pst I-, BamHIor Xhol-digested miDNA with the maize atp6 gene probe. The probe revealed similar hybridization patterns for mtDNA from Group I cms lines when digested with any one of the three restriction enzymes, as represented in Fig. 8, which shows BamHI-restricted mtDNA from various $\mathrm{cms}$ lines hybridized to the at $\mathrm{p} 6$ probe. The hybridization patterns of $\mathrm{mtDNA}$ from $\mathrm{cms}$ lines $\mathrm{L} 67$, PMC 23, DSA 118 and DSA 134 digested with either

Fig. 5 Southern hybridization of the 4.7-kb pearl millet clone to $X$ hol-digested $\mathrm{mtDNA}$ from $\mathrm{cms}$ and their maintainer lines. Lanes 1 and $2 \mathrm{PMC} 23 \mathrm{~A}$ and $\mathrm{B}$, and 3 and $45141 \mathrm{~A}$ and $\mathrm{B}, 5 \mathrm{DSA} 134 \mathrm{~A} 6$ and 7 DSA $105 A$ and $B, 8$ and 9 PMC $30 A$ and $B, 10$ and 11 DSA $118 A$ and $B, 12$ and 13 DSA $144-1$ A and $B$. Note the presence ( $>$ ) of $\mathrm{a} 20-\mathrm{kb}$ and absence ( $>$ ) of a 7-kb fragment in $5141 \mathrm{~A}$ and PMC $30 \mathrm{~A}$ (lanes 3 and 9, respectively)

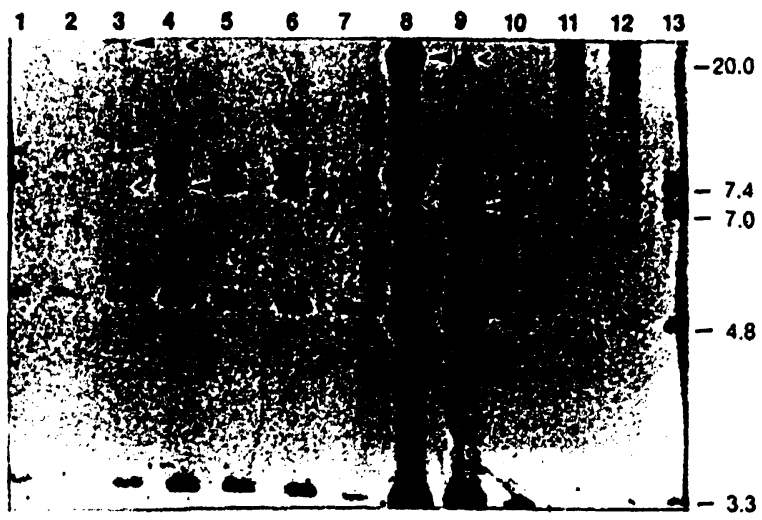

Fig. 6 Southern hybridization of the maize at $p 9$ gene clone to $X$ holdigested mtDNA from cms lines. Lane I PMC 30A, 2 L 67 A, 3 PMC 23A, 4 DSA 59-1A, 5 DSA 105A, 6 DSA 118A, 7 DSA 134A, 8 DSA 144-1A, 981 A4, 10 ICMA 88001, II ICMA2. Arrow'( ) indicates the presence of a fragment

Pst or BamHI and probed with the atp6 clone were similar, whereas cms line DSA 144-1A showed some variation, as represented in Southern blots of Pst I-digested miDNA (Fig. 10a, lane 5). The digests of $\mathrm{mtDNA}$ with $X$ hol showed identical hybridization patterns between $\mathrm{cms}$ lines L 67 and PMC 23, cms lines DSA 105 and DSA 118, and cms lines DSA 59-1 and DSA 134. whereas DSA 144-1 showed a pattern distinct from all of the above $\mathrm{cms}$ lines (Fig. 9, lane 8). A prominent 3.6-kb $X$ hol fragment present in most cytoplasms was absent in DSA 144-1A and 81 A4 (Fig. 9, lanes 8 and 9, respectively). The hybridization patterns of $\mathrm{mtDNA}$ from $\mathrm{cms}$ lines 88001 and $81 \mathrm{~A} 4$ digested with either Pst I, BamHI 


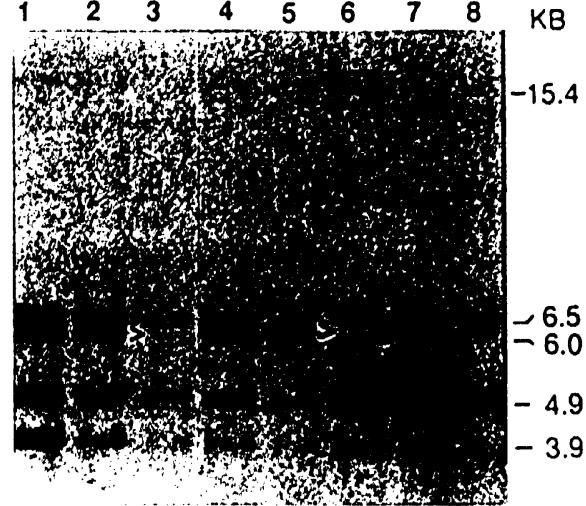

Fig. 7 Autoradiogram of maize coxl gene clone hybridized to BamHI-digested miDNA from cms lines. Lane I ICMA 1, 2 ICMB I, 3 PMC 30A, 4 PMC 23A, 5 L 67 A, 6 ICMA 88001, 781 A4, 8 ICMB 2. Airow's $(>)$ indicate the absence of fragments

or $X$ hol and probed with atp6 were distinct from each other as well as from the other cms lines (Fig. 10b).

\section{Analysis of dendrograms}

The dendrogram constructed on the basis of similarity indices among various $\mathrm{cms}$ pairs following hybridizations of Pst I-, BamHI-, SmaI- or Xhol-digested mtDNA with four pearl millet clones revealed two distinct

Fig. 8 Autoradiogram of the maize atp6 gene clone hybridized to BamHI-digested mIDNA from cms lines. Lane I ICMA 1, 2 ICMA 2, 3 5141A, 4 PMC 30A, 5 L 67A, 6 PMC 23A, 7 DSA 59-1A, 8 DSA 105A, 9 DSA 118A, 10 DSA 134A. M Molecular markers (i. DNA digested with HindIII)

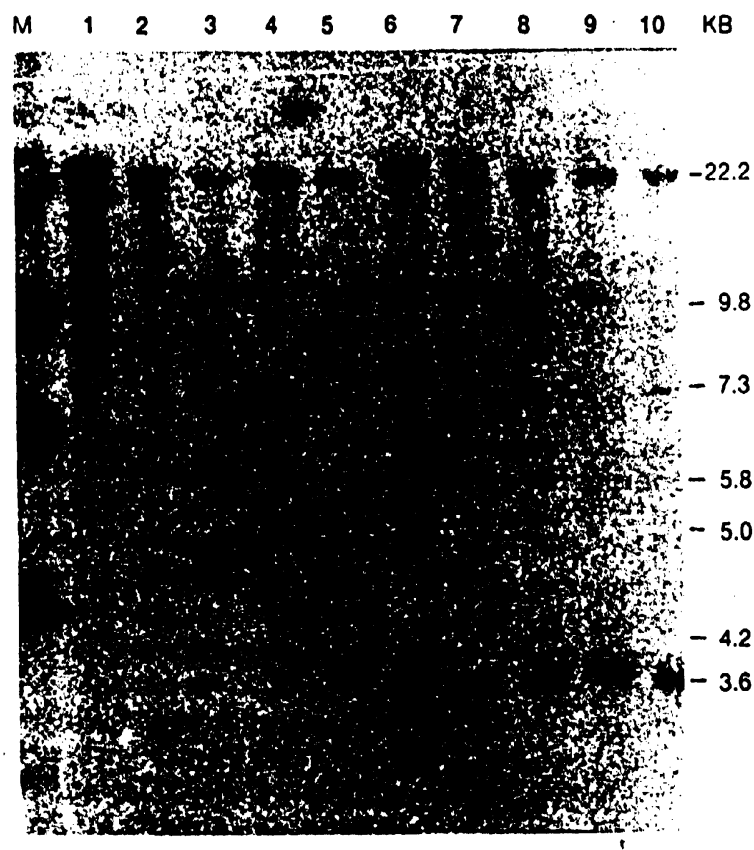

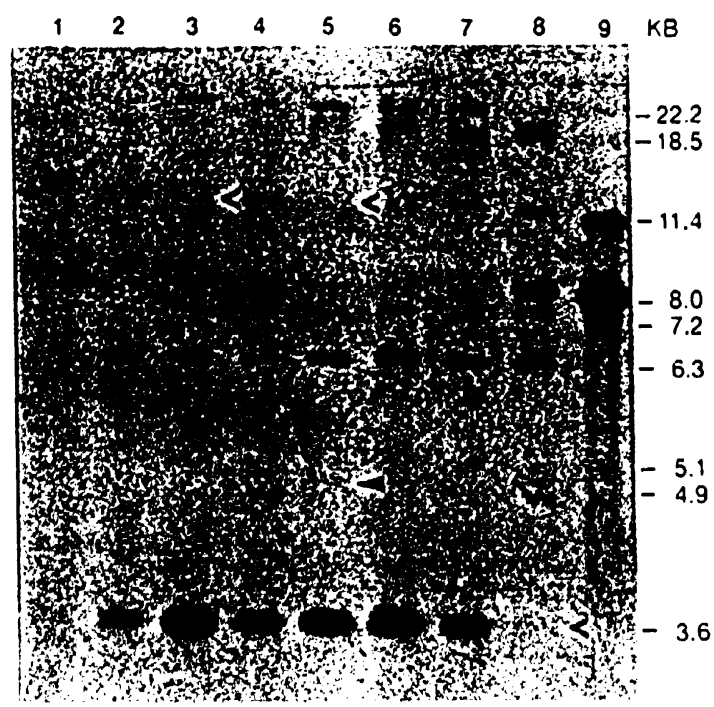

Fig. 9 Southern hybridization of the maize atp6 gene clone to $X$ hoIdigested mtDNA from cms lines. Lane I PMC 30A, 2 L 67A, 3 PMC 23A, 4 DSA 59-1A, 5 DSA 105A, 6 DSA 118A, 7 DSA 134A, 8 DSA 144-1A, 981 A4. Arrow's indicate the presence ( $)$ /absence ( $>$ ) of fragments

groups with $F=0.8$ as the significance limit (Fig. 11). The male-sterile line $5141 \mathrm{~A}$, ICMA 1, ICMA 2 and PMC 30A formed a distinct cluster, while the remaining $9 \mathrm{cms}$ lines formed a second cluster widely separated from the first cluster. Three subgroups were evident

Fig. $10 \mathrm{a}, \mathrm{b}$ Southern hybridization of the maize atp6 gene clone to Pstl-digested miDNA from cms lines. a Lane I ICMA 1, 2 PMC 30 A, 3 L 67A, 4 PMC 23A, 5 DSA 144-1A, 6 ICMA-2. b Lane I ICMA 88001.281 A4
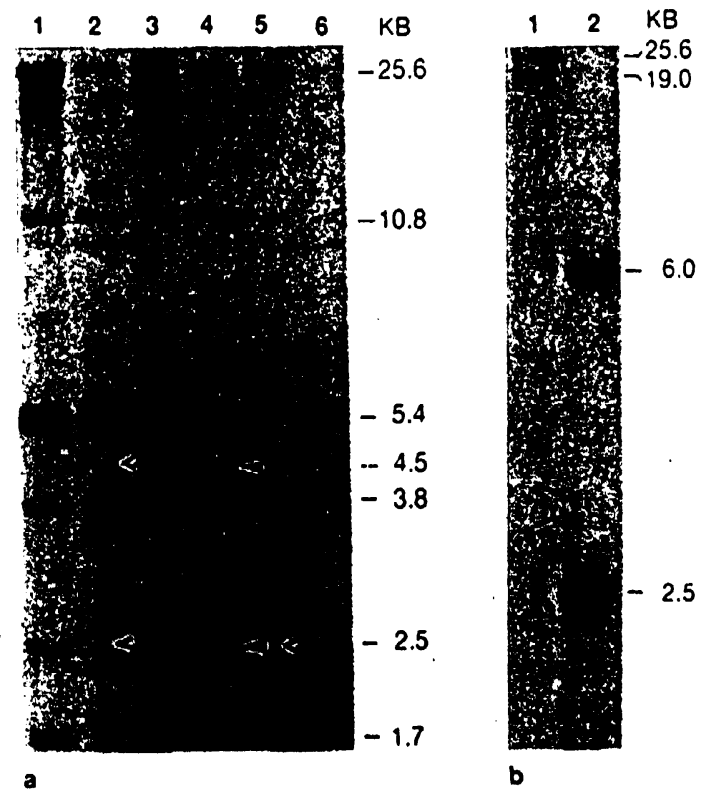

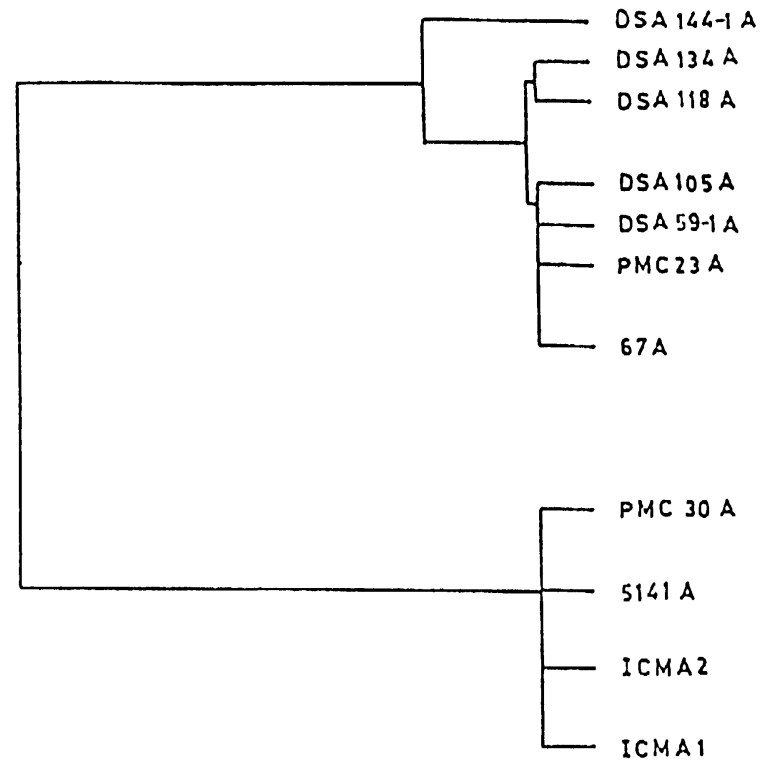

$\begin{array}{llllll}0 & 1 & 1 & 1 \\ 0.2 & 0.4 & 0.6 & 0.8 & 1.0 \\ & & \text { Similarity index }\end{array}$

Fig. 11 Dendrogram of cms lines of pearl millet based on homologous miDNA clones and four restriction enzymes. The dendrogram was constructed on the basis of similarity indices among the various cms lines following hybridization of Pst l-, BamHI-. Smal-or $X$ hol-digested miDNA with the four pearl millet clones as described in the Materials and methods

Fig. 12 Dendrogram of $\mathrm{cms}$ lines of pearl millet based on maize atp6 gene clone and three restriction enzymes. The dendrogram w'as constructed on the basis of similarity indices among the various $\mathrm{cms}$ lines following hybridization of Pst]-, BamHI- or Xhol-digested mtDNA with the maize atp6 clone as described in the Materials and methods

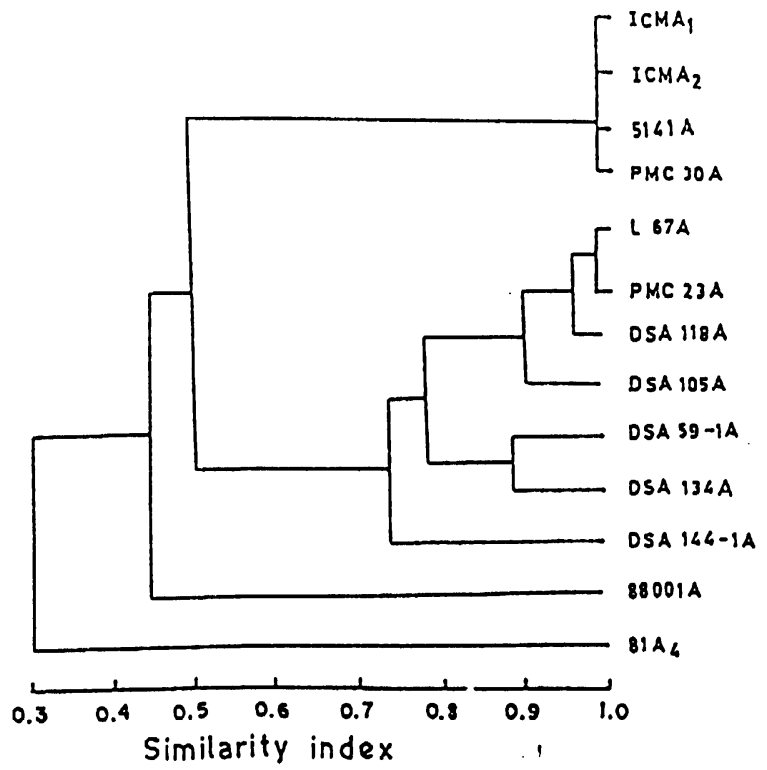

within the second cluster: male-sterile lines L 67A, PMC 23A, DSA 59-1A and DSA 105A form a close cluster, differing slightly from DSA 118A and DSA 134A, which were clustered together; DSA 144-1A showed a $20 \%$ variation from the others.

The dendrogram based on the similarity indices generated from hybridization patterns of $\mathrm{mtDNA}$ digested with Pst I, BamHI or Xhol and probed with the maize atp6 clone revealed four groups (Fig. 12) at a level of significance equivalent to the first dendrogram $(F=0.75)$. PMC 30A, 5141A, ICMA 1 and ICMA 2 formed a distinct cluster similar to that seen with the homologous clones. Four subgroups were evident within the second group of cytoplasms. Cytoplasmic malesterile line $81 \mathrm{~A} 4$ and ICMA 88001 were distinct from each other as well as from all the other cms lines.

\section{Discussion \\ Detection of polymorphism based on restriction patterns}

The method of Smith et al. (1987), involving the use of low viscosity, high ionic strength, saline buffers (Bookjans et al. 1984), combined with a stringent washing of the mitochondria with a high salt buffer, potassium acetate precipitation to remove polysaccharides and lipids (Dellaporta et al. 1983) and the precipitation of the nucleic acids with isopropanol-ammonium acetate consistently yielded mtDNA that could be digested with restriction enzymes. However, the yield and purity of the mtDNA varied among the different preparations depending on the genotype and source of tissue used for extraction. In general, mtDNAs obtained from soft stem tissues showed better restriction patterns than those from etiolated seedlings. Restriction patterns have been reported to provide a reliable method to characterize male-sterile cytoplasms in pearl millet (Smith and Chowdhury 1989), whereas under our conditions, the patterns were not consistently clear across the accessions. Therefore, Southern hybridizations using miDNA specific clones were used to study polymorphisms in various cms lines.

\section{Detection of polymorphism using homologous} clones

Hybridization patterns of PstI-, BamHI-, SmaI- or $X$ hol-digested mtDNA when probed with any one of the four pearl millet mtDNA clones distinguished Group I cytoplasms consisting of $5141 \mathrm{~A}$, ICMA 1, ICMA 2 and PMC 30A from the Group II male-sterile lines, L 67A, PMC 23A, DSA 59-1, DSA 105A, DSA 118A, DSA 134A and DSA 144-1A as well as their maintainer (fertile) B-lines. On the basis of fertility restoration studies, cms lines 5141 A (Pokhriyal et al. 1976) derived from Tift 23A cytoplasm and ICMA 1 (Andrews and 
Anand Kumar 1982) have been earlier classified as one group, designated S-Al (Smith et al. 1987). According to the present data, cms lines PMC 30A (derived from Botswana accessions) and ICMA 2 could also be grouped as S-Al cytoplasms. The four pearl millet mtDNA clones used as probes were PstI fragments associated with reversion to fertility in the S-A1 type of cytoplasms (Smith et al. 1987). These clones revealed two sets of homologies following double digestions with various restriction enzymes (Smith and Chowdhury 1991): the 9.7- and 13.6-kb clones shared one set of homology, while the 13.6-, 10.9- and 4.7-kb clones with the rrn18-rrn5 and coxI genes mapped on them showed a second set of homology. The S-Al cytoplasms were characterized by the presence of a $4.7-\mathrm{kb}$ Pst I fragment and an additional 4.9-kb BamHI, 7.5-kb Smal and 20-kb $X$ hol fragment instead of the 10-kb Pst I, 6-kb BamHI, 6-kb Simal and 7-kb Xhol fragments present in the remaining cytoplasms; the other fragments hybridizing to the four clones were common to all cytoplasms. The 4.7-kb Pst fragment to which the rm18-rrns and coxI genes are mapped is present only in the S-Al cytoplasms; this corresponds to the $10-\mathrm{kb}$ Pst I fragment in the remaining $\mathrm{cms}$ lines and also in their maintainer (fertile) cytoplasms. This suggests that rearrangements in the min18-mns and/or coxI genes are probably responsible for S-Al type of sterility, as has been suggested by Smith et al. (1991).

Detection of polymorphism using heterologous clones

Hybridization patterns using maize mtDNA gene probes revealed further differences among the $\mathrm{cms}$ lines of pearl millet. The at $p 9$ probe distinguished $\mathrm{cms}$ line 81 A4, derived from $P$. glaucum subsp. monodii and previously classified as the S-Am cytoplasm (Smith and Chowdhury 1989). The maize coxI probe distinguished the S-Al type of cytoplasm similar to the pearl millet clones.

The maize atp6 clone distinguished a wide range of cytoplasms. The four main groups of cytoplasms revealed by the atp 6 probe agreed in general with the classification arrived at by breeders using fertility restoration studies. PMC 30A, $5141 \mathrm{~A}$, ICMA 1 and ICMA 2 formed a distinct cluster, whereas L 67A, previously classified as S-A3 cytoplasm (Burton and Athwal 1967) along with PMC 23A, DSA 118A, DSA 105A, DSA 59-1A, DSA 134A and DSA 144-1A (identified from Botswana and Ghana accessions; Appa Rao et al. 1989) formed another cluster within which further variations were evident. Most of these accessions are stable cms lines possessing several desirable agronomic traits. This variation among the cytoplasms could be of great value in the production of hybrids in different cytoplasmic backgrounds, thus providing greater variability. A similar variation was reported by Weihe et al. (1991) among eight $\mathrm{cms}$ lines of Beta vulgaris derived from the same source of cytoplasm (Owen's cytoplasm) collected from various research stations, following hybridization of mtDNA with the maize coxII gene probe.

In pearl millet, $81 \mathrm{~A} 4$ and ICMA 88001 were distinct from each other as well as from all of the other $\mathrm{cms}$ lines. 81 A4 showed patterns similar to the S-Am group of cytoplasms reported by Smith and Chowdhury (1989). ICMA 88001 , however, was distinct from all of the cms lines being derived from P. violaceum (Lam.) L. Rich (Marchais and Pernes 1985).

Additional fragments in mtDNA of $\mathrm{cms}$ lines other than the S-Al type (Fig. 8) hybridized to the maize atp6 gene clone with varying intensities, indicating the presence of more copies of this gene with different stoichiometries. This suggests rearrangements in the mitochondrial genome at the atp 6 region that probably lead to the formation of chimeric genes.

The present study revealed polymorphisms in the $m t D N A$ from $\mathrm{cms}$ lines and their maintainer lines of pearl millet. Homologous clones could identify one group of cytoplasms, whereas differences among the remaining cytoplasms could only be detected using heterologous probes. The enzyme-probe combinations which differentiated various cytoplasms in the present study would aid in the identification of specific clones. Selection of clones based on the enzyme-probe combinations specific for a particular type of cytoplasm or unique transcripts or translational products would enable us to identify genes responsible for sterility.

Acknowledgements We sincerely thank Drs. S. Appa Rao and K. N. Rai, ICRISAT, for providing us with the necessary seed material. We thank Mr. D. Midya, ICRISAT for help in cluster analyses. We acknowledge the help of Mr. R. Luke in the lab experiments. International Crops Research Institute for the Semi-Arid Tropics (ICRISAT) Journal Article No. 1416.

\section{References}

Andrews DJ, Anand Kumar K (1982) Cytoplasmic male-sterility in pearl millet (Pennisetum americanum) (L.) Leeke) - a review. Mutat Breed Newsl 20:1-3

Appa Rao S, Mengesha MH, Rajagopal Reddy C (1989) Development of cytoplasmic male-sterile lines of pearl millet from Ghana and Botswana germplasm. In: Manna GK. Sinha U (eds) Perspectives in cytology and genetics, vol 6, pp 817-823

Bailey-Serres, J, Dixon LK, Liddell AD, Leaver CJ (1986) Nuclearmitochondrial interaction in cytoplasmic male-sterile sorghum. Theor Appl Genet 73:252-260

Bookjans G, Stummann BM, Henningsen KW (1984) Preparation of chloroplast DNA from pea plastids isolated in a medium of high ionic strength. Anal Biochem 141:244-247

Borck KS, Walbot V (1982) Comparison of the restriction endonuclease digestion patterns of mitochondrial DNA from normal and male-sierile cytoplasms of Zea may's L. Genetics 102:109-128

Burton GW (1983) Breeding pearl millet. Plant Breed Rev 1:162-182

Buton GW. Athwal DS (1967) Two additional sources of cytoplasmic male sterility in pearl millet and their relationship to Tift 23A. Crop Sci 7:209-211

Dallaporta SL, Wood J, Hicks JB (1983) A plant minipreparation: version II. Plant Mol Biol Rep 4:19-21

Dewey RE, Levings CS III. Timothy DH (1985a) Nucleotide sequence of ATPase subunit 6 gene of maize mitochondria. Plant Physiol 79:914-919 
Dewey RE, Schuster AM, Levings CS III, Timothy DH (1985b) Nucleotide sequence of $F_{0}$-ATPase proteolipid (subunit 9$)$ gene of maize mitochondria. Proc Natl Acad Sci USA 82:1015-1019

Feinberg AP, Vogelstein B (1983) A technique for radiolabeling DNA restriction endonuclease fragments to high specific activity. Anal Biochem 137:266-267

Fox TD, Leaver CJ (1981) The Zea mays mitochondrial gene coding cýtochrome oxidase subunit II has an intervening sequence and does not contain TGA codons. Cell 26:315-323

Hanna WW (1987) A new stable cytoplasm in pearl millet. In: Agronomy abstracts. ASA, Madison Wis., p 64

Hanson MR, Conde MF (1985) Functioning and variation of cytoplasmic genomes: lessons from cytoplasmic-nuclear interactions conferring male-sterilities in plants. Int Rev Cytol 94:213-265

Isaac PG, Jones VP, Leaver CJ (1985) The maize cytochrome c oxidase subunit I gene: sequence, expression and rearrangement in cytoplasmic male-sterile plants. EMBO J 4:1617-1623

Marchais L, Pernes J (1985) Genetic divergence between wild and cultivated pearl millet (Pennisetum typhoides). I. Male sterility. Z Pfianz Zuecht 95:103-112

Nei M (1987) Molecular evolutionary genetics. Columbia University Press, New York
Pokhriyal SC, Unnikrishnan KV, Balzar Singh, Ram Dass, Patil RR (1976) Induction of downy mildew resistance in pearl millet male-sterile Tift 23d2. Indian J Genet 36:403-409

Smith RL, Chowdhury MKU (1989) Mitochondrial DNA polymorphism in male-sterile and fertile cytoplasms of pearl millet. Crop ScI 29:809-814

Smith RL, Chowdhury MKU (1991) Characterisation of pearl millet mitochondrial DNA fragments rearranged by reversion from cytoplasmic male sterility to lertulity. Theor Appl Genct $81: 793-799$

Smith RL, Chowdhury MKU, Pring DR (1987) Mitochondrial DNA rearrangements in Pennisetum associated with reversion from cytoplasmic male-sterility to fertility. Plant Mol Biol 9:277286

Smith RL, Chowdhury MKU, Schank SL (1989) Use of restriction fragment length polymorphism (RFLP) markers in genetics and breeding of napiergrass. Soil Crop Sci Soc Fla Proc 48:1319

Weihe A, Dudareva NA, Veprev SG, Maletsky SI, Melzer R, Salganik RI, Borner Th (1991) Molecular characierization of mitochondrial DNA of different subtypes of inale-sterile cytoplasms of sugar beet Beta vulgaris. Theor Appl Genet 82:11-16 